\title{
DE HEGEL A MARX: DA INFLEX ÃO ONTOLÓGICA À ANTÍTESE DIRETA
}

\author{
Vitor Bartoletti Sartori* \\ vitorbsartori@gmail.com
}

RESUMO Abordaremos a crítica marxiana à noção hegeliana de "ser" (Sein), mostrando que a historicidade e a objetividade, em verdade, são determinações desta (sendo as categorias, em Marx, formas de ser [Daseinsformen], determinações de existência [Existenzbestimmungen]). Deste modo, intentamos mostrar que analogias entre a lógica hegeliana e a teoria marxiana podem eclipsar aspectos centrais à abordagem materialista proposta pelo autor de "O capital". Apontando a inversão hegeliana entre sujeito e predicado, Marx trata da apreensão do real que, muito embora seja traçada em diálogo com a dialética hegeliana, é também sua antítese direta (direktes Gegenteil).

Palavras-chave Marx, Hegel, ser, objetividade (Gegenständlichkeit).

ABSTRACT We will deal with the Marxian criticism to the Hegelian notion of "being". It will be shown that historicity and objectivity are determinations of this category (and that categories are always forms of being, determinations of existence). So, the analogy between the Hegelian logic and the Marxian theory may, sometimes, hide essential aspects of the materialist comprehension of history. Here, we intend to prove that, by questioning the treatment dispensed to the matter of being by Hegel, Marx criticizes the

* Doutor em Filosofia do Direito (USP) e professor da UNESP. Artigo recebido em 08/10/2013 e aprovado em 01/07/2014.

KRITERION, Belo Horizonte, no 130, Dez./2014, p. 691-713 
Hegelian inversion between subject and predicate in a way that, although dialoguing with Hegel, his conception is the exact opposite at the same time.

Keywords Marx, Hegel, being, objectivity.

\section{1}

Excluindo Marx, Hegel foi o autor mais tratado, de um modo ou doutro, no marxismo. Aqui, tentaremos abordar um aspecto específico da crítica marxiana ao autor da "Ciência da lógica", aquele que diz respeito à confirmação da objetividade (Gegenständlichkeit) no autor e que aparece também na compreensão marxiana da noção de ser (Wesen). Trata-se de tema que tem reverberações na teoria das abstrações (Cf. Chasin, 2009), na distinção entre modo de pesquisa (Forschungsweise) e de exposição (Darstellungsweise) presente em "O capital" e, talvez no aspecto mais pungente, na crítica marxiana à inversão hegeliana entre sujeito e predicado, crítica essa realizada já na "Crítica à filosofia do Direito de Hegel" e que permanece na obra de Marx durante todo o seu desenvolvimento. Albergando estes aspectos ao passo que temos por central a crítica ao modo como se apresenta a noção de Ser (Sein) em Hegel, intentamos esclarecer aspectos importantes da diferença específica trazida ao pensamento marxiano em razão de seu embate com a filosofia hegeliana.

Adentramos tal empreitada dando enfoque à posição marxiana segundo a qual "um ser não objetivo é um não-ser" (Marx, 2004, p. 127) (Ein ungegenständliches Wesen ist ein Unwesen). Trata-se de algo essencial para conformação da posição marxiana na medida em que, para o autor, como mostraremos no final do artigo, ao contrário do que se dá em Hegel, não é essencial a diferença, e a aposição, entre o ente (Seiende), o ser (Wesen) e o Ser (Sein). Explicitamos a crítica marxiana também ao passo que estas diferenciações e oposições (que usualmente vêm a ser lidas como antinomias) aparecem de modo pungente em parte considerável da filosofia do século XX, principalmente pela influência da figura de Martin Heiddeger. Mostraremos, assim, que há em Marx a busca pelo próprio ente real e efetivo (wirklich) na medida em que "momento filosófico não é a lógica da coisa (Sache), mas a coisa da lógica" (Marx, 2005a, p. 39) (Nicht die Logik der Sache, sondern die Sache der Logik ist das philosophische Moment). Aqui, mesmo tendo em mente que um autor da monta de Lenin chegue a dizer que "não se pode compreender plenamente $O$ capital de Marx, e particularmente seu primeiro 
capítulo, sem ter estudado e compreendido toda a Lógica de Hegel" (Lenin, 2012, p. 157), acreditamos que é impossível transpor o desenvolvimento categorial da "Ciência da lógica" para a obra mestra de Marx (algo que alguns importantes estudiosos não deixam de intentar, mesmo, em nossa opinião, contra a letra do texto do próprio Marx). Não trataremos aqui do tema de modo direto, mas abordaremos aspectos que - intentamos mostrar - conformam um estudo prévio necessário e essencial quando se adentra neste meandro.

Desta maneira, antes de se rejeitar a compreensão rigorosa da diferença conformada na passagem da filosofia hegeliana à marxiana, mesmo esta passagem de Lenin - que deu legitimidade a muitas aproximações descuidadas entre Marx e Hegel -, deve ganhar destaque em função, também, das descontinuidades que marcam a diferença específica do pensamento marxiano ante o hegeliano. Pretendemos mostrar, pois, que não pode ser considerado apropriado deixar de lado o acerto de contas em relação a Hegel, acerto esse calcado, primeiramente, na denúncia feita por Marx, já em seus escritos de juventude, em que aponta que o filósofo da "Fenomenologia do espírito", em verdade, viria a transplantar - de modo sutil e instigante, claro - a esfera concreta do ser (Wesen) à esfera abstrata da lógica, realizando uma inversão sui generis entre sujeito e predicado. Para tratar da famosa (famigerada?) "inversão" marxiana é preciso ter em mente este ponto, até mesmo porque, em Hegel, a lógica é vista no mesmo patamar da realidade efetiva (Wirklichkeit) - o que se dá principalmente na "Ciência da lógica" quando se adentra a lógica do conceito (Begriff) ao passo que o Ser (Sein) é considerado uma mera abstração, trazendo Marx, como pretendemos deixar claro no texto, a posição diametralmente oposta sobre tal temática ao enfocar, em "antítese direta" (direktes Gegenteil) a Hegel, que "um ser (Wesen) não objetivo é um não-ser (Unwesen)."

\section{2}

O modo como começa a "Ciência da lógica" de Hegel é esclarecedor no que diz respeito às questões que intentamos aqui abordar. Diz-se - no início desta obra - que o Ser (Sein) é carente de determinações, é o mais abstrato, é forma pura de intuição (Anschauen). Ele, pois, corresponderia, segundo o autor alemão, à imediatez:

Ser (Sein), puro Ser (reines Sein): sem nenhuma determinação outra. Na sua imediatez indeterminada, ele é apenas igual a si mesmo e não é desigual em relação à outra coisa (gegen Anderes); ele não tem diversidade alguma no interior de si nem fora. Qualquer determinação ou conteúdo que seriam postos nele como diferentes, 
ou através do qual ele seria posto como diferente de um outro, não lhe permitiria manter-se em sua pureza. Ele é pura indeterminação e vazio (Leere). Não há nada a intuir nele, se da intuição (Anschauen) poderíamos aqui dizer; ou ele é apenas este próprio intuir, puro e vazio [...] O Ser, o imediato indeterminado é, na verdade, nada (Nichts), não mais nem menos que nada. (Hegel, 1982, p. 107)

O Ser (Sein) não aparece enquanto algo concreto e, por si, dotado de efetividade (Wirklichkeit), mas como um abstrato. Segundo Hegel, partir do Ser implicaria em apegar-se à imediatez, o que significaria deixar de lado as determinações que compõem a realidade efetiva (Wirklichkeit), em um primeiro momento, ao menos. ${ }^{1}$ No âmbito em que se apresenta a categoria do Ser, diz Hegel, não seria cognoscível a contradição e sequer poder-se-ia pensar a realidade efetiva mesma com referência à diferença, já que as assim chamadas determinações reflexivas (Reflexionsbestimmungen) só vêm à tona na "Ciência da lógica" na doutrina da essência. ${ }^{2}$ Neste momento da apresentação hegeliana, sem espaço para a diversidade, a identidade estaria amparada no Ser somente ao passo que conformaria uma forma vazia, não comportando sequer a determinação (que traz, em Hegel, consigo também a diferença). Com isso, a categoria "Ser" somente poderia constituir o início de um percurso ideal, que deveria transcorrer na medida em que há de se pressupor uma espécie de fenomenologia, ${ }^{3}$ em que o Ser só é passível de efetividade com o papel central que viria a adquirir a mediação da consciência que se eleva a um patamar superior no espírito, como mostra Hegel na "Fenomenologia do espírito".

Ao passo que para Marx "não é a consciência (Bewusstsein) que determina a vida (Leben), mas a vida que determina a consciência" (Marx; Engels, 2007, p. 94) (Nicht das Bewußtsein bestimmt das Leben, sondern das Leben bestimmt das Bewußtsein), em Hegel, a apreensão da vida passa pela mediação da consciência de tal modo que o Ser (Sein) é subsumido como um momento da última, e não da primeira - para se tratar da "inversão" marxiana de Hegel, isso é essencial. Desde logo, pois, percebe-se que, no autor da "Ciência da lógica", a apreensão da universalidade real (que, para Marx, está conformada na objetividade [Gegenständlichkeit] que vem com a

1 Diz Hegel que "o ser (Sein) puro constitui o começo, porque é tanto puro pensamento quanto é o imediato indeterminado, simples; ora, o primeiro começo não pode ser algo mediatizado e, além do mais, determinado" (Hegel, 2005a, p. 175).

2 A obra hegeliana vai ganhando concretude na medida em que se progride da doutrina do Ser (Sein) à doutrina da essência (Wesen) e, por fim, à doutrina do conceito (Begriff). A exposição hegeliana, que pretende corresponder ao movimento do próprio real, vai do abstrato ao concreto, pois.

3 Tarefa esse realizada, sobretudo, na "Fenomenologia do espírito". 
história mundial $\left.[\text { Weltgeschichte }]^{4}\right)$ não teria consigo a apreensão reta do ser (Wesen); antes, a posição hegeliana é aquela segundo a qual o real (Reale) só poderia ser apreendido ao passo que é mediado pela consciência humana já colocada no patamar da filosofia especulativa, algo que é desenvolvido, sobretudo, na "Fenomenologia do espírito". Para Hegel, em verdade, tal subsunção mencionada se dá porque o pensar e a objetividade apareceriam como suprassumidos (aufgehoben $)^{5}$ na realidade efetiva (Wirklichkeit), sendo esta última a expressão real e efetiva (wirklich) da idealidade.

No que, neste ponto, aparece o idealismo hegeliano de modo claro, mesmo que se trate de um idealismo objetivo. ${ }^{6}$ Voltemos, assim, ao que diz Hegel sobre a universalidade, pois. Diz ele sobre o início primordial da filosofia:

O universal é, pois, somente forma, e contrapõe-se lhe o particular, o conteúdo. [...] O primeiro é o universal como tal; este é o abstrato, é o pensamento, mas enquanto puro pensamento é abstração. "Ser" (Sein) ou "essência" (Wesen), , "o uno", etc., são alguns desses pensamentos de todo abstratos. (Hegel, 2005b, p. 73)

A noção de Ser (Sein) é compreendida como uma abstração inerente aos primórdios do pensamento ocidental, podendo ser encontrada na filosofia de um Parmênides, por exemplo, e sendo, em-si, carente de sentido em outro

4 Marx e Engels tratam da conformação da objetividade (Gegenständlichkeit) e da universalidade de modo real e concreto, relacionando o indivíduo singular com a totalidade social em "A ideologia alemã": "o desenvolvimento de um indivíduo é condicionado pelo desenvolvimento de todos os outros, com os quais ele se encontra em intercurso direto e indireto, e que as diferentes gerações, recebendo das anteriores as forças produtivas e as formas de intercâmbio que foram acumuladas, são elas determinadas em suas próprias relações mútuas. Em poucas palavras, é evidente que um desenvolvimento sucede e que a história de um indivíduo singular não pode ser de modo algum apartada da história dos indivíduos precedentes e contemporâneos, mas sim é determinada por ela" (Marx; Engels, 2007, p. 422).

5 Um tema importante, do qual não poderemos tratar aqui, diz respeito ao modo como o Aufhebung aparece de modo distinto em Hegel e em Marx. Aqui, utilizamos a noção, ao falar de Hegel, de modo hegeliano, o qual se explicita no autor, do seguinte modo: "Por aufheben entendemos primeiro a coisa que 'hinterwegräumen' [ab-roga], 'negieren' [negar], e por conseguinte dizemos, por exemplo, que uma lei, um dispositivo são 'aufgehoben' [ab-rogados]. Mas além disso significa também o mesmo que aufbewahren [conservar] e nesse sentido dizemos que a coisa está 'wohl aufgehoben' [bem conservada]. Esta ambiguidade no uso da língua, segundo a qual a mesma palavra tem uma significação negativa e uma significação positiva, não se pode considerar como contingente, nem se pode absolutamente fazer à linguagem a censura de dar azo à confusão; mas tem-se de reconhecer aí o espírito especulativo de nossa língua, que vai além do simples ou-ou do entendimento (Verstehen)" (Hegel, 2005a, pp. 194-195).

6 Diz Hegel: "realidade (Realität) e idealidade são consideradas muitas vezes como uma dupla de determinações que se contrapõem uma à outra com igual autonomia e, por esse motivo, se diz que fora da realidade há também uma idealidade. Ora, a idealidade não é algo que haja fora e ao lado da realidade, mas o conceito de idealidade consiste expressamente em ser a verdade da realidade, isto é, que a realidade posta como é em si, mostra-se ela mesma como idealidade" (Hegel, 2005a, p. 194).

7 Em alemão, entre outros sentidos, a noção de Wesen aparece tanto enquanto essência quando enquanto ser, sendo o primeiro uso aquele hegeliano e o segundo mais próximo de Marx que, não obstante, em outros contextos, utiliza o primeiro também. 
momento. ${ }^{8}$ Segundo Hegel, na modernidade, na sociedade civil-burguesa (bürguerliche Gesellschaft), não se poderia ter como parâmetro tal noção, a qual padeceria de indeterminação se comparada a noções que pressuporiam um desenvolvimento maior do pensamento ocidental, pressupondo igualmente a reconciliação (Versöhnung) de categorias ainda não desenvolvidas autônoma e plenamente no pensamento grego. A concretude, que contém em si a diversidade e determinações, em Hegel, apareceria somente com a noção de realidade efetiva (Wirklichkeit), mas não com o Ser. Este último seria somente parte do percurso ideal (que também é real no autor) do qual derivaria o devir (Werden) que, por seu turno, na lógica da essência - para o autor, "a verdade do Ser está é a essência” (Hegel, 1969, p. 389) (Die Wahrheit des Seins ist das Wesen) - apareceria na figura da contradição: "a efetividade (Wirklichkeit) é a unidade, que veio a ser imediatamente, da essência (Wesen) e da existência, ou do interior e do exterior." (Hegel, 2005a, p. 266). Note-se: não que o Ser não fosse importante para o autor da "Ciência da lógica". Ele é. Mas, inelutavelmente, teria uma dupla delimitação: sua inserção nos primórdios da filosofia ocidental (nos pensamentos "de todo abstratos") e seu caráter vazio, este último que conduziria o Ser ao seu oposto: "o Ser, o imediato indeterminado é, na verdade, nada (Nichts), não mais nem menos que nada." Esta copertença entre Ser e nada é essencial a Hegel.

No autor da "Ciência da lógica", da oposição entre o Ser (Sein) e o nada (Nichts) deriva o devir (Werden); e é justamente esse último que seria - em um nível de concretude maior - de grande importância para a conformação do caráter processual da racionalidade do real (Wirklichen), sendo que, para o pensador, para que se use sua frase célebre, a qual remete já à efetividade (Wirklichkeit) "o racional é real e o real é racional” (Hegel, 2003a, p. XXXVI) (Was vernünftig ist, das ist wirklich; und das wirklich ist das ist vernünftig). Ou seja, a oposição entre Ser e nada pode, até certo ponto, ser vista como uma espécie de motor interno primeiro da lógica hegeliana, a qual, assim, carrega consigo certo caráter teleológico na medida em que do Ser advém, logicamente, o devir e este somente seria compreendido tendo em conta a realidade efetiva (Wirklichkeit), em que se realiza sua essência (Wesen) de modo pleno; o caminho do imediatismo do Ser à concretude mediatizada da realidade efetiva tem por corolário a negatividade inerente à relação existente - em Hegel - entre o Ser e o nada. Portanto, se Hegel não traça um abismo entre Ser e nada, ele traz uma solução que propicia a possibilidade de se 
pensar a contraditoriedade do real que é efetivo (wirklich) (o que é um enorme avanço, segundo Marx e Engels $)^{9}$ somente ao passo que esse último vem a configurar o cume do desenvolvimento do espírito, que se desenvolve, por fim, em espírito absoluto (o que é criticado de modo decidido por Marx) - o espírito absoluto aparece como pressuposto no desenvolvimento da filosofia hegeliana, presidindo o processo de desenvolvimento das diversas figuras do espírito, dentre elas, inclusive, o espírito objetivo, a esfera da sociabilidade em que se apresentam a sociedade civil-burguesa (bürguerliche Gesellschaft) e o Estado.

Em Hegel, o modo como se pensa o Ser (Sein) somente poderia relacionarse à história da filosofia, e não à elaboração de uma filosofia que condissesse com o espírito do tempo moderno; o Ser só poderia ser efetivo (wirklich) se subsumido a figuras dotadas de mais determinações (as quais só aparecem, em Hegel, na modernidade mesma, e no pensamento moderno na medida em que "a verdade do Ser é a essência [Wesen]"). O locus do Ser estaria na Grécia antiga, não se podendo transpô-lo à sociedade civil-burguesa (bürguerliche Gesellschaft) senão naquela forma pela qual foi primordialmente exposto, e que - se tivesse alguma importância ainda, apareceria suprassumido (aufgehoben) no devir e, em um grau maior de concretude, na contradição e, por fim, na realidade efetiva (Wirklichkeit). ${ }^{10}$ Assim, Hegel expressa-se de modo enfático quanto à diferença existente entre o seu tempo e a Antiguidade clássica:

Nada é mais oco do que os apelos tantas vezes repetidos aos exemplos gregos e romanos durante a Revolução Francesa; nada é mais diferente do que a natureza destes povos e de nosso próprio tempo. (Hegel, 2004, p. 50)

O modo como aparecem a Antiguidade e os temas da filosofia antiga (segundo o autor, entre estes temas, o Ser [Sein]) é aquele de algo já superado,

9 Em oposição a este modo de pensar, Engels traz a figura da metafísica, a qual se apresentaria, também, no próprio senso comum: "à primeira vista, esse método especulativo parece-nos extraordinariamente plausível, porque é o do chamado senso comum. Mas o verdadeiro senso comum, personagem bastante respeitável, dentro de portas fechadas, entre as quatro paredes de uma casa, vive peripécias verdadeiramente maravilhosas, quando se arrisca pelos amplos campos da investigação. E método do pensamento metafísico, por justo e necessário que seja em vastas zonas do pensamento, mais ou menos extensas, de acordo com a natureza do objeto que trata, tropeça sempre, cedo ou tarde, com uma barreira, que, franqueada, faz com que ele se torne um método unilateral, limitado, abstrato; perde-se em contradições insolúveis uma vez que, absorvido pelos objetos concretos, não consegue enxergar as suas relações. Preocupado com sua própria existência, não reflete sobre sua gênese e sua caducidade; concentrado em suas condições estáticas, não percebe a sua dinâmica; obcecado pelas árvores, não consegue ver o bosque" (Engels, 1990, pp. 20-21).

10 Como mostraremos ao final de nosso texto, a posição de Marx é diametralmente oposta neste ponto. 
suprimido (aufgehoben), tratar-se-iam de temáticas que apareceriam na filosofia somente na medida em que se encontrariam elevadas a um novo patamar mais concreto em figuras como a essência (Wesen), a contradição e a realidade efetiva (Wirklichkeit). A dialética hegeliana opera por meio da categoria da superação (Aufhebung), a qual, é bom que se diga, não raro, foi transposta ao pensamento marxiano sem o devido cuidado, mesmo que, em Hegel, se trate de uma noção lógica e, nesta medida mesma, real - o que é oposto ao espírito, e à letra, marxianos. Marx diz que "em sua forma mistificada, a dialética foi à moda alemã porque ela parecia tornar sublime o existente" (Marx, 1988, p. 27). Isso se dá, em verdade, também ao passo em que oposições reais e efetivas (wirklich), bem como questões ligadas a elas, são tidas por Hegel como suprassumidas pois o presente se corporificaria como algo real e racional - "o racional é real e o real é racional." A superação (supressão, suprassunção) é compreendida de tal modo por Hegel que haveria uma lógica inerente ao próprio real (Reale), sendo fenômeno e essência, real e racional, somente pensáveis ao passo que a efetividade (Wirklichkeit) do presente é concebida como o cume do desenvolvimento do espírito, enquanto uma face da realização da ideia; a realidade efetiva aparece como expressão da ideia, e não oposto, pois. E, sabe-se, este é um dos grandes pontos em que Marx ataca Hegel.

Nesse sentido, partindo da oposição entre Ser (Sein) e nada (Nichts), passando pelo devir (Werden), a lógica hegeliana dá ensejo ao movimento do pensamento do abstrato ao concreto na medida em que o movimento do real (Wirklichen) não seria senão, ao final, aquele da razão (Vernunft). A realidade efetiva (Wirklichkeit) mesma expressaria a racionalidade, a lógica, e, assim, na medida mesmo em que o autor da "Ciência da lógica" faz uma crítica contundente às formas de consciência atreladas de modo imediato à vida cotidiana (o que seria um grande avanço, segundo Marx), ele trata de hipertrofiar o papel da razão, a qual, realizada na figura do espírito absoluto, fornece, em Hegel, o télos da própria realidade efetiva, a qual vem a aparecer enquanto realização da ideia.

O Ser (Sein), enquanto noção central à filosofia, segundo Hegel, seria uma categoria importante à Antiguidade; no presente ela somente apareceria suprassumida (aufgehoben), sendo a partir dela deduzido o devir (Werden) como parte constitutiva da própria objetividade (Gegenständlichkeit), efetiva (wirklich), por sua vez, por meio da reconciliação (Versöhnung) do ideal da realidade (Realität) na realidade efetiva (Wirklichkeit). O devir, pois, aparece como um momento da objetividade mesma em Hegel. Por outro lado, como aponta Engels, o autor da "Fenomenologia do espírito" trouxe à tona também 
algo dificilmente conciliável com isto: "um sistema universal e compacto, definitivamente plasmado, no qual se pretende enquadrar a ciência da natureza e da história" e isso "é incompatível com as leis da dialética" (Engels, 1990, p. 23). Trata-se da conhecida contradição entre o método dialético hegeliano (amparado no devir e, em um grau mais concreto na contraditoriedade do real) e seu sistema, cujo cume encontra-se - em se tratando do desenvolvimento histórico objetivo - na realização contraditória da sociedade civil-burguesa (bürguerliche Gesellschaft).

A última, mesmo vista como "o espetáculo de devassidão bem como o da corrupção e da miséria” (Hegel, 2003a, p. 169), é também, para Hegel, a forma social em que a razão (Vernunft) seria real e efetiva (wirklich) por meio de sua subsunção ao Estado. ${ }^{11}$ A racionalidade do real (Reale) é enxergada na medida em que o movimento realizado na história é a manifestação do devir (Werden) já pressuposto num duplo sentido: na medida em que decorre do impulso dado à lógica pela relação entre Ser (Sein) e nada (Nichts) - de onde é deduzido o devir -, e ao passo que o devir do real conforma-se no presente, sendo o télos rumo ao último também suposto por Hegel enquanto realização racional em-si e para-si da ideia. A ideia, pois, apresenta-se enquanto sujeito que preside o processo de desenvolvimento da objetividade (Gegenständlichkeit). E, como aponta Marx já em sua juventude, sobre Hegel:

Ele transformou em um produto, em um predicado da Ideia, o que é seu sujeito; ele não desenvolve seu pensamento a partir do objeto (Gegenständ), mas desenvolve o objeto segundo um pensamento previamente concebido na esfera abstrata da lógica. (Marx, 2005a, p. 36)

Marx destaca a prioridade ontológica do objeto (Gegenständ), criticando Hegel por ter realizado em seu "Princípios da filosofia do Direito" uma inversão sui generis em que aquilo que é sujeito, no caso analisado por Karl Marx na passagem, a constituição política (politischen Verfassung), aparece como um predicado da "ideia universal", no caso, de organismo. Aquilo que é real e efetivo (wirklich), pois aparece como a expressão de uma ideia universal, e não o oposto, como postula Marx; assim, depois de certo ponto, segundo Marx, não se tem em Hegel a compreensão reta da gênese do real (Reale); o real, assim, apresentando-se de modo um tanto quanto mistificado

11 Marx recrimina a filosofia do Direito hegeliana: "o verdadeiro interesse não é a filosofia do direito, mas a lógica. O trabalho filosófico não consiste em que o pensamento se concretize nas determinações políticas, mas em que as determinações políticas existentes se volatizem no pensamento abstrato. O movimento filosófico não é a lógica da coisa (Sache), mas a coisa da lógica. A lógica não serve à demonstração do Estado, mas o Estado serve à demonstração da lógica" (Marx, 2005a, pp. 38-39). 
("a dialética foi à moda alemã porque ela parecia tornar sublime o existente"), ocultando, quer se queira, quer não, o verdadeiro elemento real e efetivamente ativo na constituição da sociabilidade humana, a própria atividade do homem 12 - "porque se partiu da 'Ideia' ou da 'Substância' como sujeito, como essência real (dem wirklichen Wesen), o sujeito real aparece apenas como o último predicado do predicado abstrato" (Marx, 2005a, p. 38). A própria atividade que engendra formas sociais de objetividade (Gegenständlichkeit) a atividade objetiva (gegenständliche Tätikeit) -, sob circunstâncias legadas pelo passado, ${ }^{13}$ aparece de modo esfumaçado no autor da "Ciência da lógica", passando a ser vista como o resultado predicado pela ideia tornada substância. A objetividade hegeliana, portanto, não aparece como uma objetividade fantasmagórica e hipostasiada, isto é verdade. Não se trata de uma abordagem que fetichiza o real. Isto, porém, somente se dá ao passo que há uma posição idealista clara segundo a qual "a realidade (Realität) posta como é em si, mostra-se ela mesma como idealidade" (Hegel, 2005a, p. 194) (Realität als das gesetzt, was sie an sich ist, erweist sich selbst als Idealität). Se o autor criticado por Marx escapa da armadilha kantiana - que consiste em traçar um abismo entre a cognição racional e a coisa-em-si (Ding an sich) - ele vem a enxergar a superação (Aufhebung) do imediatismo como um procedimento que só é possível ao se conceber o sujeito como um predicado da ideia, a qual, por sua vez, traria consigo a reconciliação (Versöhnung) entre sujeito e objeto (Objekt) na figura do "sujeito-objeto idêntico". Hegel, pois, trata de desenvolver uma forma de crítica ao agnosticismo kantiano que, ao final, redunda na identidade entre sujeito e objeto: em Hegel, somente enquanto se compreende o caráter das figuras da consciência (Bewusstsein) - que aparecem como sujeito, e não predicado - que a realidade (Realität) aparece como efetividade (Wirklichkeit). A prioridade ontológica do objeto, apontada como decisiva por Marx, resta eclipsada, tendo-se, não a compreensão da legalidade específica da coisa (Sache), mas a subsunção da coisa às leis da lógica.

Segundo Marx, "Hegel, por toda parte, faz da Ideia o sujeito e do sujeito propriamente dito [...] faz o predicado. O desenvolvimento prossegue, contudo, sempre do lado do predicado" (Marx, 2005a, p. 32). O "lado do predicado" -

12 Como diz Marx em uma conhecida passagem: "ser radical é agarrar a coisa pela raiz. Mas a raiz, para o homem, é o próprio homem” (Marx, 2005b, p. 151). Diz ainda nos "Grundrisse”: "Indivíduos produzindo em sociedade - por isso, o ponto de partida é, naturalmente, a produção dos indivíduos socialmente determinada" (Marx, 2011, p. 54).

13 Aponta Marx que "os homens fazem a sua própria história, mas não a fazem segundo a sua livre vontade; não a fazem sob circunstâncias de sua escolha e sim sob aquelas com que se defrontam diretamente, legadas e transmitidas pelo passado. A tradição de todas as gerações mortas oprime como um pesadelo o cérebro dos vivos" (Marx, 1997, p. 21). 
leia-se, as formas ideológicas ${ }^{14}$ que vêm a ser essenciais na conformação do momento ideal da atividade humana e que são, até certo ponto, hipostasiadas por Hegel - parecem ter prioridade sobre a conformação objetiva do real (Reale) somente na medida em que, aponta Marx, isto em verdade não se dá e nem pode se dar. A lógica só pode ganhar a proeminência que têm no autor da "Ciência da lógica" quando este é levado pela "lógica da coisa", e não pela "coisa (Sache) da lógica", ocorrendo o oposto em Marx que, novamente, já em sua juventude, inverte o hegelianismo traçando a prioridade ontológica do Ser (Sein) sobre a consciência: para o autor de "O capital", "a consciência (Bewusstsein) não pode ser jamais outra coisa que o Ser consciente (bewusste Sein), e o Ser dos homens é seu processo de vida real" (Marx; Engels, 2007, p. 94) (Das Bewußtsein kann nie etwas Andres sein als das bewußte Sein, und das Sein der Menschen ist ihr wirklicher Lebensprozeß). Vê-se, novamente, pois, que a vida (Leben) e o Ser antecedem a consciência, sendo os primeiros a base real da última - a prioridade ontológica, mencionada anteriormente (em relação ao objeto [Gegenständ]) aparece, assim, em um grau maior de concretude, em que se apresenta, em verdade, a consciência como um predicado do Ser consciente.

A inversão marxiana, pois, tem um estatuto ontológico, tratando-se da prioridade do ser (Wesen) real e efetivo (wirklich) mesmo sobre questões de método. ${ }^{15}$

No que a crítica de Marx a Hegel ganha um tom que nos parece ser de grande relevo, como veremos a seguir: O autor da "Ciência da lógica" ainda busca apresentar uma filosofia que seja sistemática enquanto corresponde o desenvolvimento espiritual ao desenvolvimento do espírito absoluto e à razão (Vernunft) mesma. De acordo com os paradigmas de sua época, aponta algo que deve ser visto em seu aspecto intimamente contraditório: "a verdadeira figura em que a verdade existe só pode ser o seu sistema científico" (Die wahre

14 Aponta Marx de modo preciso a prioridade ontológica da objetividade (Gegenständlichkeit) conformada na base material da atividade humana na seguinte passagem, em que também trata da noção de "formas ideológicas": "convém distinguir sempre a transformação material das condições econômicas de produção - que podem ser verificadas fielmente com ajuda das ciências físicas e naturais - e as formas jurídicas, políticas, religiosas, artísticas e filosóficas, em resumo, formas ideológicas, sob as quais os homens adquirem consciência desses conflitos e o levam até o fim" (Marx, 2009, p. 46).

15 Aponta acertadamente Chasin neste sentido algo essencial sobre o assunto, sendo suas palavras precisas: "se por método se entende uma arrumação operativa, a priori, da subjetividade, consubstanciada por um conjunto normativo de procedimentos, ditos científicos, com os quais o investigador deve levar a cabo seu trabalho, então não há um método em Marx. Em adjacência, se todo o método pressupõe um fundamento gnosiológico, ou seja, uma teoria autônoma das faculdades humanas cognitivas, preliminarmente estabelecida, que sustente ao menos parcialmente a possibilidade do conhecimento, ou, então, se envolve e tem por compreendido um modus operandi universal da racionalidade, não há, igualmente, um problema do conhecimento na reflexão marxiana" (Chasin, 2009, p. 89). 
Gestalt, in welcher die Wahrheit existiert, kann allein das wissenschaftliche System derselben sein), buscando o autor o seguinte: "colaborar para que a filosofia se aproxime da forma da ciência - da meta em que deixe de chamarse amor ao saber para ser saber efetivo - é isto o que me proponho" (Hegel, 2003b, p. 27) (ihren Namen der Liebe zum Wissen ablegen zu können und wirkliches Wissen zu sein ist es, was ich mir vorgesetzt). Aqui também aparece de modo pungente a contradição, apontada por Engels, entre sistema e método: a filosofia hegeliana é declaradamente sistemática somente na medida em que esta sistematicidade mesma procura se colocar como "saber efetivo" (wirkliches Wissen), ou seja, como o saber que é real e efetivo (wirklich), que alcança a concretude da realidade efetiva (Wirklichkeit). O autor da "Ciência da lógica", assim, torna a filosofia autônoma para depois fazê-la retornar à realidade (Realität), realizando, também neste ponto, a inversão entre sujeito e predicado apontada por Marx em sua juventude (em Hegel, a realidade efetiva pressupõe o desenvolvimento espiritual, e não o oposto). Contra isso, a posição de Marx não deixa de ser antípoda:

Ali onde termina a especulação, na vida real (wirklichen Leben), começa também, portanto, a ciência real, positiva (wirkliche, positive Wissenschaft), a exposição da atividade prática (Darstellung der praktischen Betätigung), do processo prático de desenvolvimento dos homens (des praktischen Entwicklungsprozesses der Menschen). (Marx; Engels, 2007 p. 95)

Assim, para o autor de "O capital", a ciência (o saber real e efetivo [wirklich]) não aparece como um predicado da atividade engendrada pelo idealismo especulativo (em que realidade [Realiät] e idealidade convergem na realidade efetiva [Wirklichkeit]) - antes, ela começa onde o primeiro termina: "as fraseologias sobre a consciência (Bewusstsein) acabam e o saber real (wirkliches Wissen) tem de tomar seu lugar. A filosofia autônoma perde, com a exposição da realidade (Darstellung der Wirklichkeit), seu meio de existência" (Marx; Engels, 2007, p. 95). E isto nos parece essencial.

A crítica marxiana ao idealismo hegeliano busca a própria "exposição da realidade" (Darstellung der Wirklichkeit), a explicitação das determinações da realidade efetiva (Wirklichkeit), sendo este procedimento alheio a qualquer autonomização da filosofia, mesmo que esta, posteriormente, como em Hegel, sofresse uma reconciliação (Versöhnung) e aparecesse "elevada a um nível superior" na realidade efetiva, dando ensejo à efetividade. Trata-se, em Marx, como já mencionado, da prioridade ontológica do objeto (Gegenständ), que, claro, não se reduz ao objeto inerte (Objekt) enquanto instância constitutiva da realidade efetiva, não podendo ser desconsiderada tal prioridade por uma 
posição que se pretenda materialista, como a de Marx. No último, a atividade humana mesma é atividade objetiva (gegenständliche Tätikeit), ${ }^{16}$ que leva a cabo - até certo ponto ${ }^{17}$ - a conformação da objetividade (Gegenständlichkeit) que se apresenta socialmente em meio às relações sociais de determinado momento do desenvolvimento histórico objetivo. Marx e Engels apontam, neste sentido, que "conhecemos apenas uma ciência, a ciência da história" (Marx; Engels, 2002, p. 107) (Wir kennen nur eine einzige Wissenschaft, die Wissenschaft der Geschichte), na medida em que se trata de uma ciência em que a totalidade social aparece por meio da "exposição da realidade" (Darstellung der Wirklichkeit) mesma e não em relação a qualquer lógica ou qualquer metodologia autonomizados.

Para Marx, a conformação da sociedade civil-burguesa (bürguerliche Gesellschaft) não é o resultado da realização da razão (Vernunft) na história do espírito humano, mas parte da "pré-história da sociedade humana" (Marx, 2009, p. 48), da "história de todas as sociedades que existiram", "a história da luta de classes" (Marx; Engels, 1998, p. 9). O autor de "O capital" parte da crítica à sociedade civil-burguesa, cuja anatomia, diz, "deve ser procurada na economia política" (Marx, 2009, p. 47). Assim, pode-se dizer que Marx, opondo-se a Hegel, fala de uma "configuração racional" da dialética na qual "não se deixa impressionar por nada e é, em sua essência (Wesen), crítica e revolucionária (kritisch und revolutionär)" (Marx, 1988, pp. 20-21) na medida em que questiona a própria conformação real e efetiva (wirklich) da sociedade em que se situa; partindo dos apontamentos de Marx, assim, seria necessária uma transformação no campo do próprio Ser (Sein), da própria realidade efetiva (Wirklichkeit) e, tendo isto em mente, primeiramente, diz Karl Marx que de modo decidido que em suas "Teses sobre Feuerbach":

16 Marx é preciso em sua crítica ao materialismo de Feuerbach: "o principal defeito de todo o materialismo existente até agora (o de Feuerbach incluído) é que o objeto (Gegenständ), a realidade, o sensível, só é apreendido sob a forma do objeto (Objekt) ou da contemplação, mas não atividade humana sensível, como prática; não subjetivamente. Daí o lado ativo, em oposição ao materialismo, [ter sido] abstratamente desenvolvido pelo idealismo - que, naturalmente, não conhece a atividade real, sensível, como tal. Feuerbach quer objetos sensíveis (sinnliche Objekt), efetivamente diferenciados dos objetos do pensamento: mas ele não apreende a própria atividade humana como atividade objetiva (gegenständliche Tätigkeit). Razão pela qual ele exagera, n' A essência do cristianismo, apenas o comportamento teórico como o autenticamente humano, enquanto a prática é apreendida e fixada apenas em uma forma de manifestação judaica, suja. Ele não entende, por isso, o significado da atividade 'revolucionária', práticocrítica" (Marx; Engels, 2007, p. 533).

17 Há sempre de se ter em conta a autonomia da objetividade ante a consciência, algo essencial em qualquer posição materialista. 
A questão de saber se ao pensamento humano cabe alguma verdade objetiva (gegenständliche Wahrheit) não é uma questão de teoria, mas uma questão prática. [...] A disputa acerca da realidade (Wirklichkeit) ou não realidade (Nichtwirklichkeit) de um pensamento que se isola da prática é uma questão puramente escolástica. (Marx; Engels, 2007, p. 537)

A impossibilidade da autonomização da esfera ideal quanto à objetiva (gegenständliche) é clara na passagem, passagem esta a qual não deixa de remeter à posição segundo a qual "a consciência (Bewusstsein) não pode ser jamais outra coisa que o Ser consciente (bewusste Sein), e o Ser dos homens é seu processo de vida real (ist ihr wirklicher Lebensprozeß)" - o processo de vida real (mediado pelas relações sociais de produção, que se expressam na época de Marx na sociedade civil-burguesa) é, em Marx, o momento em que se deve enfocar - desatrelar as categorias deste processo é deixar de tratá-las como "formas de ser (Daseinformen), determinações de existência (Existezbestimmungen)". Caso este procedimento criticado por Marx seja adotado, tem-se o caráter escolástico criticado pelo autor de "O capital". Para Marx, a verdade objetiva (gegenständliche Wahrheit) mesma aparece como uma questão prática na medida em que não se mostra possível uma exposição que não tenha em conta as categorias como partes constitutivas do real (Reale); a atividade objetiva do homem não é, pois, expressão da idealidade, ou uma mera perda de si nos objetos sensíveis (sinnliche Objekt). O tertium datur marxiano se apresenta quando se enfoca a prioridade ontológica do objeto (Gegenständ), enxergando a atividade humana na conformação da objetividade (Gegenständlichkeit) ao passo que esta traz consigo uma tensão entre a conformação e atual da sociabilidade humana e aquela que, com a mediação da práxis, pode ser realizada uma vez já estando presente como possibilidade (Möglichkeit).

A atividade prática do homem, pois, é central para o autor alemão somente na medida em que há uma precedência das condições reais e concretas que se apresentam a ele na sua cotidianidade. Trata-se, como menciona Marx em uma passagem já citada do "18 Brumário", de circunstâncias com as quais os homens se "defrontam diretamente, legadas e transmitidas pelo passado. A tradição de todas as gerações mortas oprime como um pesadelo o cérebro dos vivos." É, pois, da maior importância, a apreensão reta destas circunstâncias, tratando-se, em Marx, da "configuração racional" da dialética somente ao passo que esta última exprime o movimento mesmo do real (Reale), e não qualquer modelo, por mais complexo e elaborado que ele mostre ser: o "momento filosófico não é a lógica da coisa (Sache), mas a coisa da lógica." Este momento não é vão, pois. Mas, sempre, deve reconhecer a prioridade da 
objetividade (Gegenständlichkeit), e a prioridade ontológica do próprio objeto (Gegenständ).

No que se deve adentrar em um meandro importante: é preciso dizer que a distinção entre modo de exposição (Darstellungsweise) e modo de pesquisa (Forschungsweise) - de grande importância para Marx - é, de certo modo, estranha a Hegel. Na medida em que, no autor idealista, as categorias já são concebidas como componentes do próprio real (Reale), há certa autonomização das instâncias que apreendem as primeiras, a filosofia e a lógica (mesmo que essas, depois, voltem-se à realidade efetiva [Wirklichkeit] no autor). Com o ímpeto sistemático do pensamento hegeliano, poder-se-ia ainda deduzir logicamente as categorias eivadas de maior grau de concretude a partir das categorias anteriores (tal qual o devir [Werden] foi deduzido da oposição entre Ser [Sein] e nada). Assim, ao contrário do que se dá em Marx, a apreensão efetiva (wirklich) da real tessitura da realidade efetiva somente é possível tendo em mente o locus específico de cada uma das categorias em relação ao desvelamento lógico da categoria precedente; no caso aqui tratado, o Ser aparece como uma categoria primeira para o autor da "Ciência da lógica", sendo ele cognoscível somente neste momento da exposição, sendo o mais abstrato, aquilo carente de determinações. Ao enxergar aquilo que é real e efetivo como a expressão da ideia (na diç̧ão de Marx, de uma "ideia universal") algo essencial poderia, segundo o autor de "O capital", ser negligenciado; trata-se justamente daquilo que Marx julgou ser de maior relevo: "captar detalhadamente a matéria (Stoff), analisar suas formas de evolução e sua conexão íntima” (Marx, 1988, p. 26). E isso não seria algo contingente na posição hegeliana, não sendo possível, pois, qualquer transposição da lógica e da dialética hegelianas ao universo categorial marxiano: no início da lógica hegeliana mesma já estaria certo logicismo, que se apresenta na inversão entre sujeito e predicado. Para Marx, pois, deve-se "captar detalhadamente a matéria, analisar suas formas de evolução e sua conexão íntima" de modo que seja possível explicitar as determinações reais e efetivas da realidade efetiva, com a "exposição da realidade" (Darstellung der Wirklichkeit) mesma. À luz do que dissemos, resta clara a passagem de "O capital":

Por sua fundamentação, meu método dialético não só difere do hegeliano, mas é também sua antítese direta (direktes Gegenteil). Para Hegel, o processo de pensamento, que ele, sob o nome de ideia, transforma num sujeito autônomo, é o demiurgo do real (Demiurg des Wirklichen), real que constitui apenas sua manifestação externa. Para mim, pelo contrário, o ideal não é nada mais que o material (Materielle), transposto e traduzido na cabeça do homem. (Marx, 1988, p. 26) 
A prioridade ontológica do objeto (Gegenständ) fica explícita na passagem também enquanto Marx reitera, em sua obra madura, a crítica que já tecera em sua juventude acerca da inversão sui generis realizada por Hegel entre sujeito e predicado - neste ponto específico há uma "antítese direta" (direktes Gegenteil) entre o "método dialético" de Marx, método esse que procura expressar as categorias como formas de ser (Daseinformen), determinações de existência (Existenzbestimmungen) ao passo que "o ideal não é mais que o material (Materielle) transposto e traduzido ${ }^{18}$ na cabeça do homem", e o método de Hegel que toma a ideia como algo autonomizado ante a concretude para, então, fazer com que ela se volte a esta como um demiurgo, que conformaria real e efetivamente (wirklich) a realidade efetiva (Wirklichkeit). É mesmo importante notar que não há também qualquer tipo de spinozismo no autor de "O capital" na medida em que há uma autonomia relativa do pensamento que não pode ser desconsiderada - o ideal é um momento, mas um momento subsumido ao processo de vida real (wirklicher Lebensprozeß) que marca a conformação da realidade efetiva em Marx também, certamente. No entanto, isto se dá na medida em que as formações ideais trazem consigo a apreensão da objetividade (Gegenständlichkeit), que têm uma prioridade ontológica; "captar detalhadamente a matéria (Stoff), analisar suas formas de evolução e sua conexão íntima" é aquilo que constitui o momento essencial da relação estabelecida entre a objetividade e o momento ideal no processo de vida. Reiterando aquilo já mencionado, para Marx, "a consciência (Bewusstsein) não pode ser jamais outra coisa que o Ser consciente (bewusste Sein), e o Ser dos homens é seu processo de vida real (Sein der Menschen ist ihr wirklicher Lebensprozeß)".

No que é preciso tratar com cuidado de alguns destes aspectos, colocados na medida mesma em que Marx não autonomiza a ideia para depois reconciliála com a realidade efetiva (Wirklichkeit), nem vê a última como a expressão da ideia, a qual, como mencionou o autor de $O$ capital, aparece em Hegel como um demiurgo.

Para Marx, "é, sem dúvida, necessário distinguir o método de exposição (Darstellungsweise), formalmente, do método de pesquisa (Forschungsweise)" (Marx, 1988, p. 26). De tal feita que a investigação (Forschung) precisa, como mencionado, "captar detalhadamente a matéria (Stoff), analisar suas formas de evolução e sua conexão íntima." E, então, "só depois de concluído esse trabalho é que se pode expor adequadamente o movimento real" (Marx, 1988, como importante a atividade humana na cognição do real. 
p. 26). Se para o autor da "Ciência da lógica", o real (Wirklichen) aparece como um fruto do pensamento que - por meio de uma série de suprassunções (Aufhebung) concatenadas logicamente - sintetiza a si mesmo, tendo tal processo sido presidido pelas suas próprias determinações, o oposto se dá em Marx, dado que "o ideal não é nada mais que o material (Materielle), transposto e traduzido na cabeça do homem.” E, assim, é preciso que se note, neste momento de nossa exposição, que nos "Grundrisse" há uma passagem importante sobre este tema, tema este que, em Hegel, é indissolúvel do motor interno da dialética, o qual está posto na oposição entre Ser (Sein) e nada (Nichts), de que advém o devir (Werden).

O concreto é concreto porque é a síntese de múltiplas determinações, portanto, unidade da diversidade. Por essa razão, o concreto aparece no pensamento como processo da síntese, como resultado, não como ponto de partida, não obstante seja o ponto de partida efetivo (der wirkliche Ausgangspunkt) e, em consequência, também o ponto de partida da intuição e da representação (Ausgangspunkt der Anschauung und der Vorstellung). Na primeira via, a representação plena (die volle Vorstellung) foi volatilizada em uma determinação abstrata; na segunda, as determinações abstratas levam à reprodução do concreto por meio do pensamento. Por isso, Hegel caiu na ilusão de conceber o real (das Reale) como resultado do pensamento que sintetiza-se em si, aprofunda-se em si e movimenta-se a partir de si mesmo, enquanto o método de ascender do abstrato ao concreto é somente o modo do pensamento de apropriar-se do concreto, de reproduzi-lo como um concreto mental (geistig Konkretes). (Marx, 2011, pp. 77-78)

O concreto certamente é mais complexo que o objeto inerte (Objekt), o qual, no entanto, tem uma prioridade ontológica sobre a esfera ideal. Justamente por a concretude ser síntese, possuindo determinações múltiplas, que são históricas e são conformadas de modo objetivo (gegenständlich) também, pela própria atividade objetiva (gegenständliche Tätigkeit), há de se perceber que as formações ideais operam real e efetivamente (wirklich) na medida em que podem acrescentar determinações na matéria, determinações estas, as quais, porém, estavam já presentes enquanto potencialidade (Möglichkeit) na própria objetividade (Gegenständlichkeit). A existência ideal de determinado objetivo presente na imaginação do homem é parte do processo constitutivo do próprio real (Reale); a vontade do homem, no entanto, não é simplesmente demiúrgica, ela tem como esfera de ação as formas de evolução e a conexão íntima da matéria (Stoff) e da própria objetividade (Gegenständlichkeit) que, entretanto, o homem busca transformar. ${ }^{19}$ Destacamos isso na medida em que 
Marx destaca também "lado ativo, em oposição ao materialismo, [ter sido] abstratamente desenvolvido pelo idealismo - que, naturalmente, não conhece a atividade real, sensível, como tal" (Marx; Engels, 2007, p. 533) (Die tätig Seite im Gegensatz zu dem Materialismus vom dem Idealismus - der natürlich dir wirkliche, sinnliche Tätigkeit als solche nicht kennt-entwickelt). Assim, "o concreto aparece no pensamento como processo de síntese" na medida em que a "atividade real, sensível" (wirkliche, sinnliche Tätigkeit) é essencial, sendo as categorias, como já mencionado, formas de ser (Daseinsformen), determinações de existência (Existenzbestimmungen).

O concreto é ponto de partida efetivo (der wirkliche Ausgangspunkt), mas é preciso que se tenha em conta a necessidade de abstrações, um tipo de "abstração razoável (verständige Abstraktion), na medida em que efetivamente (wirklich) destaca e fixa o elemento comum" (Marx, 2011, p. 56) ao aspecto que se trata em cada caso. Primeiramente, a "representação plena" (die volle Vorstellung) é "volatilizada em uma determinação abstrata", para, somete então, "as determinações abstratas" levarem "à reprodução do concreto por meio do pensamento" (Cf. Chasin, 2009).

Sem o devido cuidado, isso soa muito próximo de Hegel, é preciso que se destaque; no entanto, também aqui, trata-se de uma "antítese direta" (direktes Gegenteil) por parte de Marx: em consonância com a prioridade ontológica do objeto (Gegenständ), e com a distinção entre modo de pesquisa (Forschungsweise) e de exposição (Darstellungsweise), o autor de "O capital" rejeita a posição segundo a qual "o real (Reale) aparece como resultado do pensamento que se sintetiza em si, aprofunda-se em si e movimenta-se a partir de si mesmo"; esta seria a posição de Hegel que, assim, justapõe modo de exposição (Darstellungsweise) e modo de pesquisa (Forschungsweise)" na medida mesma em que enxerga o sujeito real e concreto segregado da sua real atividade objetiva (gegenständliche Tätigkeit) e da "atividade real, sensível" (wirkliche, sinnliche Tätigkeit) e, assim, traz o sujeito como um predicado da ideia, a qual, teria como suposta a reconciliação (Versöhnung) entre sujeito e objeto (Objekt) na figura do "sujeito-objeto idêntico". A posição marxiana, também neste ponto, é "antítese direta": se em Hegel se parte do abstrato ao concreto na medida em que há uma concatenação lógica em que uma categoria traz in nunce sua sucessora em uma escalada de suprassunções

que já no início deste existiu na imaginação do trabalhador, e, portanto, idealmente. Ele não apenas efetua uma transformação na forma da matéria natural; realiza ao mesmo tempo, na matéria natural seu objetivo, que ele sabe que determina, como lei, a espécie e o modo de atividade e ao qual tem subordinada sua vontade" (Marx, 1988, pp. 142-143). 
(Aufhebung) concebidas logicamente e já colocadas previamente pelas determinações presentes no espírito absoluto (em última análise, na própria filosofia hegeliana enquanto cume deste), em Marx, "o método de ascender do abstrato ao concreto é somente o modo do pensamento de apropriar-se do concreto, de reproduzi-lo como um concreto mental (geistig Konkretes)".

O concreto, pois, aparece como o resultado: de um lado, da "exposição da realidade" (Darstellung der Wirklichkeit), realizada historicamente com a atividade objetiva (gegenständliche Tätigkeit), doutro, no campo do pensamento, aparece o concreto como o resultado da compreensão (Verstehen), que não prescinde da abstração razoável (verständige Abstraktion) de elementos essenciais ao processo histórico que, com a mediação da atividade humana, conflui na realidade efetiva (Wirklichkeit).

\section{4}

No que, por fim, é preciso que nos voltemos ao modo como Karl Marx enxerga aquilo que vem sendo destacado como essencial em sua posição materialista - a prioridade ontológica da objetividade (Gegenständlichkeit). Somente agora podem aparecer de modo mais concreto algumas reverberações da crítica de Marx à noção hegeliana de Ser (Sein). Elas figuram como parte importante da conformação da filosofia marxiana, sendo proveitoso, para que possamos dar uma conclusão ao nosso raciocínio, atentarmos a isto. Uma passagem de Marx explicita o que trazemos aqui - diz o autor, após apontar a objetividade como uma determinação do ser (Wesen) e dizer que "um ser não objetivo (ungegenständliches) é um não-ser (Unwesen)" - tal ser:

Assenta um ser (Wesen), que nem é ele próprio objeto (Gegenständ) nem tem um objeto. Um tal ser seria em primeiro lugar, o único ser (einzige Wessen), não existiria nenhum ser fora dele, ele existiria isolado ou solitariamente. Pois, tão logo existam objetos fora (ausser) de mim, tão logo eu não esteja só, sou um outro, uma outra efetividade (Wirklichkeit) que não o objeto fora de mim. Para este terceiro objeto eu sou, portanto, uma outra efetividade que não ele, isto é, sou seu objeto. Um ser que não é objeto de outro ser, supõe, pois, que não existe (unwirkliches) nenhum ser objetivo (unsinnliches). Tão logo eu tenha um objeto, este objeto tem a mim como objeto. Mas um ser não objetivo (ungegenständliches Wesen) é um ser da abstração. Ser sensível (Sinnlich sein), isto é, ser efetivo (wirklich sein), é ser objeto do sentido (Gegenständ des Sinn), ser objeto sensível (sinnlich Gegenständ), e, portanto, ter objetos sensíveis fora de si, ter objetos de sua sensibilidade. Ser sensível (sinnlich sein) é ser padecente (leibend sein). (Marx, 2004, p. 128)

Um primeiro aspecto a ser destacado é o caráter externo (ausser) da objetividade (Gegenständlichkeit), que independe da consciência (Bewusstsein) 
do sujeito, o qual não é outra coisa que o ser consciente (Bewusste Sein) Marx, assim, volta-se contra a posição segundo a qual haveria um único ser (einzige Wessen) que, na dicção hegeliana, conformaria o Ser (Sein) carente de determinações, pura intuição (Anschauen), que, passando pelo nada (Nichts) conflui no devir (Werden). Assim, destacando o caráter objetivo (gegenständlich) do ser (Wesen), aponta o autor de "O capital" que "um ser que não tenha nenhum objeto fora de si não é nenhum ser objetivo" (Marx, 2004, p. 127) (Ein Wesen, welches keinen Gegenstand außer sich hat, ist kein gegenständliches Wesen). Ou seja, a objetividade tem uma existência objetiva que, até certo ponto, independe da mediação da consciência, tratandose de algo que pressupõe, não a identidade entre sujeito e objeto (Objekt) hegeliana, mas a autarquia do objeto ante o sujeito. Para Marx, é sem sentido (unsinnlich) partir de ser isolado, desse único ser, dado que este último nem se apresenta como um objeto do sentido (Gegenständ des Sinn), ser objeto sensível (sinnlich Gegenständ) - para que se use a dicção das "Teses sobre Feuerbach", como objeto sensível ainda inerte (sinnliche Objekt) - e nem tem efetividade (Wirklichkeit). Segundo Marx, para que se trate de realidade efetiva (Wirklichkeit), não se tem por central um processo presidido pela ideia, processo esse que, em Hegel, é lógico, racional e real ao mesmo tempo; antes, tem-se que o caráter objetivo do ser se manifesta na medida em que o próprio sujeito só é pensável em sociedade na medida em que, quando se fala de um ser que é objeto para outro ser, já se tem em conta tanto a relação do homem com a natureza, quanto as relações nas quais os homens relacionamse entre si: dizer que "o ponto de partida é, naturalmente, a produção dos indivíduos socialmente determinada" somente faz sentido, no autor de "O capital", quando estas questões que aqui abordamos são tidas em conta com cuidado.

Segundo Marx, o ser (Wesen) não é qualquer existência abstrata que figure como o Ser (Sein) hegeliano; trata-se de entes (Seienden) os quais se conformam objetivamente na medida em que se trata do objeto sensível (sinnlich Gegenständ) enquanto "ser sensível (Sinnlich sein), isto é, ser efetivo (wirklich sein), é ser objeto do sentido (Gegenständ des Sinn) [...] e, portanto, ter objetos sensíveis fora de si, ter objetos de sua sensibilidade", sensibilidade esta inseparável da vida (Leben) (a qual, é bom lembrar, determina a consciência [Bewusstsein]). Deste modo, objetivamente, "o ser do homem é seu processo de vida real" (das Sein der Menschen ist ihr wirklicher Lebensprozeß) e, assim, a compreensão da realidade efetiva (Wirklichkeit) somente é possível fora das hierarquias colocadas por Hegel entre a razão (Vernunft), a intuição (Anschauen), a sensibilidade e o entendimento (Verstehen) - todos estes têm 
objetividade (Gegenständlichkeit) na medida em que são partes constitutivas da atividade objetiva (gegenständliche Tätigkeit), a qual, por seu turno, traz consigo também as carências humanas, as necessidades mais básicas (e também as mais elaboradas). Assim, ao final, tem-se que o homem é incompreensível sem sua base real (destacada por Marx, primordialmente, na "Ideologia alemã"), sendo seu processo de vida real (wirklicher Lebensprozeß) também o processo em que se conforma como ser sensível e pelo qual se coloca a si enquanto objeto dos sentidos, ao passo que sua autoprodução é sua formação sensível, concreta, determinada e o seu ser padecente (leibend sein).

Vê-se, pois, que um assunto aparentemente alheio aos embates pelos quais se dá a conformação do pensamento marxiano, como aquele que diz respeito à noção de Ser (Sein), e que vem sendo estudado pelos marxistas que se propõem a estudar a ontologia (no exterior, aqueles que estudam o Lukács maduro e, no Brasil, além daqueles que estudam Lukács, aqueles que partem do filósofo brasileiro José Chasin), pode figurar como algo de grande relevo na investigação da obra do autor alemão. Não só podemos perceber que, sem o devido cuidado, certas analogias entre o modo de exposição (Darstellungsweise) presente na "Ciência da lógica" e aquele de "O capital" podem trazer uma compreensão equivocada quanto a Marx; notamos também uma verdadeira inflexão ontológica no pensamento marxiano, inflexão esta que nos leva a compreender a dialética marxiana, sob o aspecto da prioridade ontológica do objeto (Gegenständ) e de sua relação com a lógica, como a antítese direta (direktes Gegenteil) da hegeliana.

\section{Referências}

CHASIN, J. "Marx: estatuto ontológico e resolução metodológica". São Paulo: Boitempo, 2009.

ENGELS, F. "Anti-Dühring”. Rio de Janeiro: Paz e Terra, 1990.

HEGEL, G. W. F. "Science of logic". Tradução de A. V Miller. Nova York: Muirhead Library of Philosophy, 1969.

. "Ciência de la logica". Tradução de Augusta e Rodolfo Mondolfo. Buenos Aires: Solar, 1982.

. "Enzyklopädie der philosophischen Wissenschaften im Grundrisse". In:

Hegel Werke. Band 8. Frankfurt: Suhrkamp, 1986a.

. "Phänomenologie des Geistes". In: Hegel Werke. Band 3. Frankfurt: Suhrkamp, 1986b.

"Vorlesungen über die Philosophie der Geschichte". In: Hegel Werke. Band

12. Frankfurt: Suhrkamp, 1986c. 
1986d.

. "Wissenschaft der Logik I". In: Hegel Werke. Band 5. Frankfurt: Suhrkamp, "Wissenschaft der Logik II". In: Hegel Werke. Band 6. Frankfurt: Suhrkamp, 1986e.

. "Grundlinien der Philosophie des Rechts". In: Hegel Werke. Band 7. Frankfurt: Suhrkamp, 1989.

"Princípios da filosofia do Direito". Tradução de Orlando Vittorino. São

Paulo: Martins Fontes, 2003a.

. "Fenomenologia do espírito". Tradução de Paulo Menezes. Petrópolis: Vozes, $2003 b$.

. "A razão na História". Tradução de Beatriz Sidou. São Paulo: Centauro, 2004.

. "Enciclopédia das ciências filosóficas". Vol. I: A ciência da lógica. Tradução de Paulo Menezes. São Paulo: Loylola, 2005a.

. "Introdução à história da filosofia". Tradução de Heloisa da Graça Burati.

São Paulo: Rideel, 2005 b.

LENIN, V. "Cadernos filosóficos". Tradução de José Paulo Netto. Rio de janeiro: UFRJ, 2012.

MARX, K. "Grundrisse der Kritik der politichen ökonomie". Berlin: Dietz, 1953. . "Das Kapital I". In: Marx/Engels Werke. Band 23. Berlin: Dietz, 1968. "Zur Kritik der Polischen Ökonomie". In: Marx/Engels Werke. Band 13. Berlin: Dietz, 1971.

. "Zur Kritik der Hegelschen Rechtsphilosophie". In: Marx/Engels Werke. Band 1. Berlin: Dietz, 1981.

1982.

“Ökonnomich-philosophische Manuskripte”. In: MEGA 1,2. Berlin: Dietz,

. “O Capital”, Vol. I. Tradução de Regis Barbosa e Flávio R. Kothe. São Paulo: Nova Cultural, 1988.

. "Grundrisse". Tradução de Martin Nicolaus. London: Penguin Books, 1993.

. "O 18 Brumário de Luiz Bonaparte". Tradução de Leandro Konder e Renato

Guimarães. Rio de Janeiro: Paz e Terra, 1997.

"Manuscritos econômico-filosóficos". Tradução de Jesus Ranieri. São

Paulo: Boitempo, 2004.

. "Crítica da filosofia do direito de Hegel". Tradução de Rubens Enderle e Leonardo de Deus. São Paulo: Boitempo, 2005a.

. "Crítica à filosofia do Direito de Hegel”. Introdução. In: K. Marx. Crítica da filosofia do direito de Hegel. Tradução de Rubens Enderle e Leonardo de Deus. São Paulo: Boitempo, 2005b.

. "Contribuição à crítica da economia política". Tradução de Florestan Fernandes. São Paulo: Expressão Popular, 2009.

. "Grundrisse". Tradução de Mario Duayer. São Paulo: Boitempo, 2011. 
MARX, K.; ENGELS, F. "Manifest der Kommunistischen Partei”. In: Marx/Engels Werke. Band 5. Berlin: Dietz, 1959.

. "Die deutsche Ideologie". In: Marx/Engels Werke. Band 3. Berlin: Dietz, 1968.

. "O Manifesto Comunista". Tradução de Maria Lucia Como. Rio de Janeiro: Paz e Terra, 1998.

. "Ideologia alemã". Tradução de Rubens Enderle. São Paulo: Boitempo, 2007. 